\title{
Effects of Irradiation by UV- Acceleration on Mechanical Properties of Polymer Blends (Polyester: Starch)
}

\author{
Sihama I. Salih Qahtan A. Hamad \\ Safaa N. Abdul Jabbar \\ Najat H. Sabit \\ Materials Eng. Dep., University of Technology \\ Baghdad, IRAQ \\ $\mathrm{Al}$ - Furat General Company for Chemical \& \\ Pesticides Industries, Baghdad, IRAQ \\ Sihama_Salih@yahoo.com qah84@yahoo.com
}

Received: 17-Oct.-2017Ｒevised: 06-Dec.-2017 Accepted: 04- Jan.-2018

http://doi.org/10.29194/NJES21010147

\begin{abstract}
This work covers mixing of unsaturated polyester (un- polyester) with starch powders as polymer blends and study the effects of irradiation by UV-acceleration on mechanical properties of its. The unsaturated polyester was mixing by starch powders at particle size less than $(45 \mu \mathrm{m})$ at selected weight fraction of $(0,0.5,1,1.5,2,2.5$ and $3 \%$ ). These properties involve ultimate tensile strength, modulus of elasticity, elongation percentage, flexural modulus, flexural strength, fracture toughness, impact strength and hardness. The results illustrate decrease in the ultimate tensile strength at and elongation percentage, while increasing modulus of elasticity, with increasing the weight ratio of starch powder to 3 $\%$ weight fraction, whereas the maximum value of hardness and flexural, impact properties happened at $1 \%$ weight fraction for types of polymer blends.
\end{abstract}

Key words: UV, Polymer Blend, Polyester, Starch, Tensile, Flexural, Impact and Hardness Tests.

\section{1- Introduction}

A composite material is formed when two or more materials are combined on microscopic scale to gives properties of composite are different (usually better) from those of the individual constituents. This material consists of two main part (matrix material and reinforcing materials), the matrix material usually soft and weak but the reinforcing materials are hard and strong [1].

It was reported that the properties of composite materials depend on shape and size of particles, particles surface area, physical properties of particles, weight fraction of reinforcement materials in the composites and adhesion force between matrix and metal particles [2 and 3].

Alaa A. Abdul-Hamead et al. studied composite material properties of polyester material reinforced with iron weave wires with percentage (5, 10, 15 and $20 \%)$. And concluded that most physical properties have been improved and the values increased with reinforcement content [4].

C.S. Obayi et al. investigated the effect of carbon black with (1 to $11 \%$ ) $\mathrm{V}_{\mathrm{f}}$ on the tensile behavior of polyester. Results showed that mechanical properties including tensile strength, toughness and elongation percentage) improved as $V_{\mathrm{f}}$ of carbon black increased from until 5\% and the maximum values was at $5 \%$. While modulus of elasticity showed constant behavior until to $5 \%$ and then increased as weight ratio increased to (11\%) [5].

The other studies were showed changes in behavior of the composite properties and their effects by any adding on it. The objective of this research is to assess the mechanical properties of polymer blends loaded by starch.

\section{2- Materials are used}

In this work unsaturated polyester resin has been used, provided from (Gulf Chemicals and Industrial Oils Company- Saudi Arabia), this type has density $1.12 \mathrm{~g} / \mathrm{cm}^{3}$ and maximum work temperature $170{ }^{\circ} \mathrm{C}$. Powder fillers that used were starch supplied from (turkey), starch powder has been sieved and the chosen particle size is less than $(45 \mu \mathrm{m})$.

\section{3- Preparation of Polymer Blends}

The polymer blends specimens are prepared by using casting methods, type (hand lay-up) method. Glass mold which have the dimensions of $(25 \mathrm{~cm} \times 25 \mathrm{~cm} \times 5 \mathrm{~mm})$ used to prepare the samples in this work, the glass mold is shown in Fig. (1).

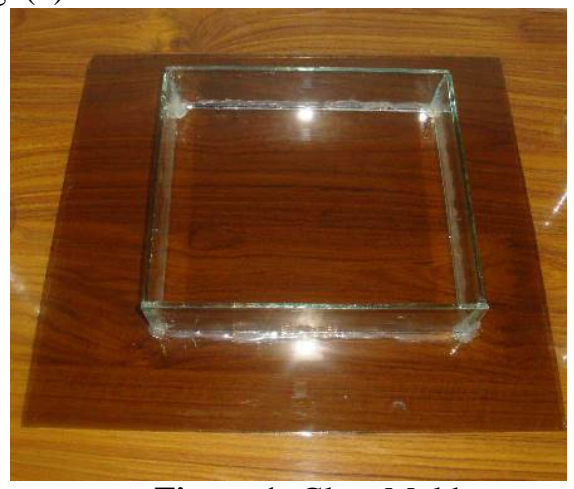

Figure 1: Glass Mold. 
Starch powders were mixed with unsaturated polyester resin with $(0.5,1,1.5,2,2.5$ and $3 \%)$ in terms of weight fraction, then blend polymer was poured into cavity of glass mold and cure for (48 hr) at $\left(27^{\circ} \mathrm{C}\right)$. All the specimens were then post cured in an oven at $\left(50^{\circ} \mathrm{C}\right)$ for $(3 \mathrm{hr})$, according to manufacturer's instructions. Then the sheets were cut off and machined according to standard specifications to produce samples conforming for mechanical properties test, for example the experimental standard of these specimen as shown in Fig. (2).

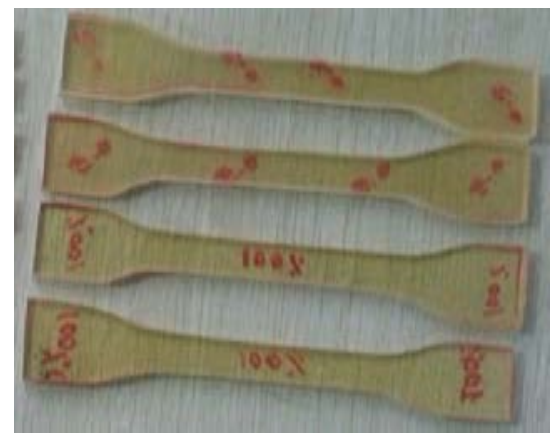

(a)

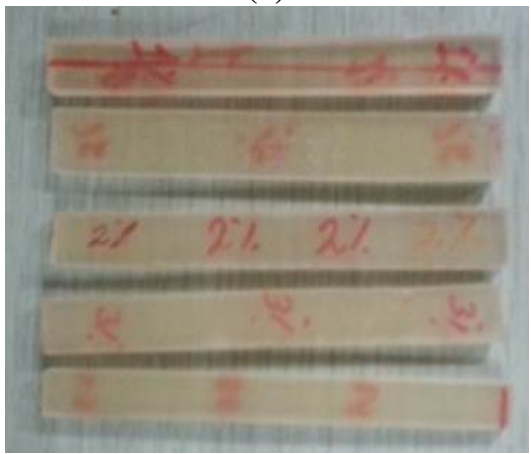

(b)

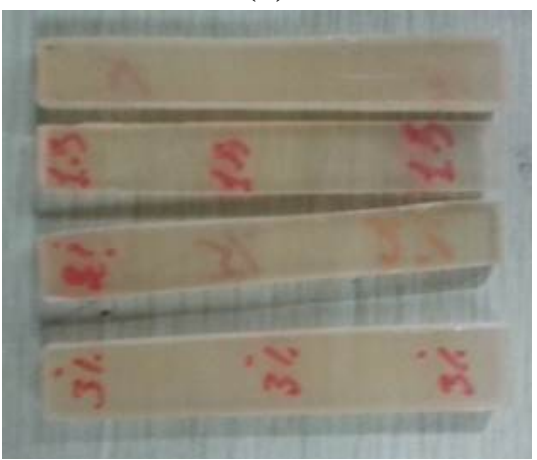

(c)

Figure 2: Experimental Standard Specimen of (a): Tensile test (b): Bending test (c): Impact test.

\section{4- Mechanical Tests}

Accordance to ASTM D-638 of tensile test, the polymer blend specimens were prepared to this test. A universal tensile testing machine was used to conduct a test at a constant cross head speed of the order $2 \mathrm{~mm} / \mathrm{min}$. The load was applied until the fracture of the specimen and the behavior of the (stress -strain) curve was drawn, the tensile test machine as shown in Fig. (3). Impact test is performed according to ISO 179. While bending (flexural) test is performed according to ASTM D-790 of by using 3-point bending test to measure the bending properties. While the hardness test were done on the specimens by using durometer type (shore-D) according to ASTM D-2240 [6, 7 and 8]. All were carried out at room temperature $\left(23 \pm 2{ }^{\circ} \mathrm{C}\right)$, then six specimens were used for most tests and final results represent the average value.

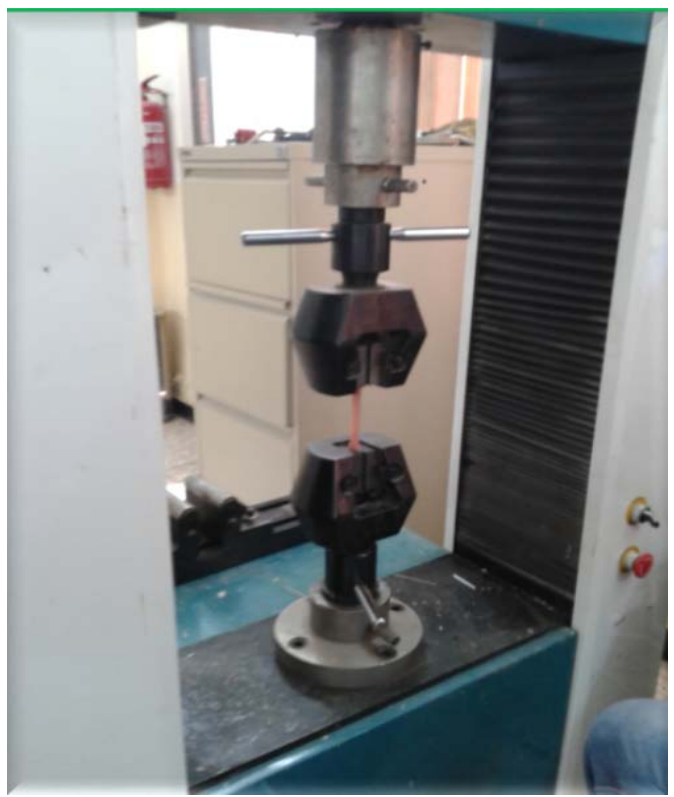

Figure 3: Tensile Test Device.

\section{5- Results and Discussion 5-1 Tensile Test Results}

Tensile test results Fig. (4) of unsaturated polyester blend reinforced by starch particles shows that the stress-strain curve behavior changed from (strong and tough) for unsaturated polyester to (soft and weak) when the weight fraction of starch powder reach to $3 \%$ in the polymer blend, then the behavior takes back to (soft and weak) and still have lower tensile values as compared with unsaturated polyester. These results related to starch powders, the major problem of polymer blending (unsaturated polyester with starch) is a very poor compatibility between hydrophilic starch and hydrophobic unsaturated polyester which gives small ability to resist tensile stress. To compare the effect of UV on polymer blend addition with the same ratio of starch on the stress-strain curves of polymer blend without UV are shown in Fig. (4). There was significant change occurs in stress-strain behavior for each type of polymer blend. As it mentioned in the above the behavior was changed from (hard and tough) for polymer blend, to (soft and weak) for unsaturated polyester resin [9 and 10]. 
The tensile properties, which include ultimate tensile strength at break $(\sigma)$, modulus of elasticity (E) and elongation $(\varepsilon)$, of unsaturated polyester blend are shown in Figures (4, 5 and 6) respectively. It can be noticed from Fig. (4) the decrease in ultimate tensile strength for both groups of polymer blend with the increasing in the weight fraction of starch powders in unsaturated polyester. The decrease in tensile stress values may be related to the nature of starch micro particles which they have poor compatibility hydrophobic unsaturated polyester resin. Also it has been observed from Fig. (5) the modulus of elasticity, for both groups of polymer blend increases with adding the weight fraction of starch powders in unsaturated polyester. However, it can be observed from Figures (4 and 5 ), that the tensile strength at break and modulus of elasticity values for the polymer blend which was reinforced by starch powder and has not exposed to UV irradiation, slightly higher than thus values of polymer blend which has exposed directly to UV irradiation, and that may be related to the effect of UV on polymer blend which cause degradation of unsaturated polyester resin molecule.

Whereas the effect of adding of starch powder on the values of elongation percentage of the polymer blend shown in Fig. (6), generally, it can be noticed from this figure that the decrease in elongation percentage for both groups of polymer blend with the increasing in the weight fraction of starch powders in unsaturated polyester. Also, it has been noticed from this figure that there was an increase in elongation percentage values for polymer blend samples when exposed directly to UV irradiation, as compared with their counterparts of polymer blend samples which has not exposed to UV irradiation and such a behavior may be related to absorb ultraviolet (UV) radiation and then undergo photolytic, photooxidative, and thermo-oxidative reactions and that result in the a photodegradable of these materials [11 and 12].

The photo-induced degradation process can be initiated by the absorption of the photon by the unsaturated polyester chains itself and/or by starch powders which incorporated in the polymer blend. The degraded sites act as stress concentrators and crack will occur when the material is subjected to stress. Thus, they diminish the tensile strength and ultimately cause the mechanical failure of the material. As well as, increase in elongation percentage values for polymer blend samples, this is due to a breakage in the main and secondary bonds as a result of absorption of photons by polymer chains when exposure to ultraviolet (UV) radiation, and this lead to increasing the movement of polymer chains and then increasing the elongation at fracture [11 and 13].

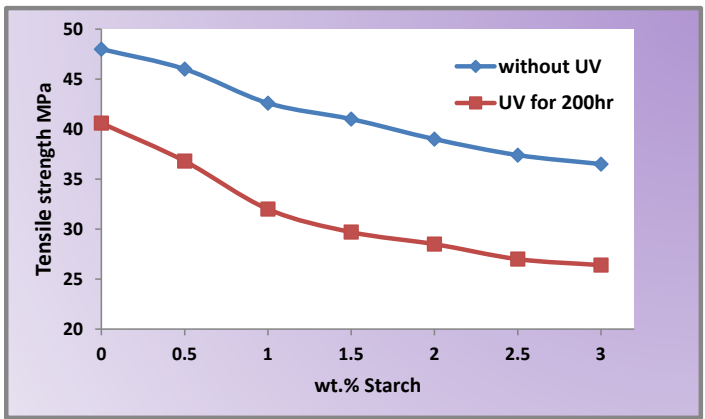

Figure 4: Tensile strength of blend (Polyester: Starch) and weight fraction of starch powder.

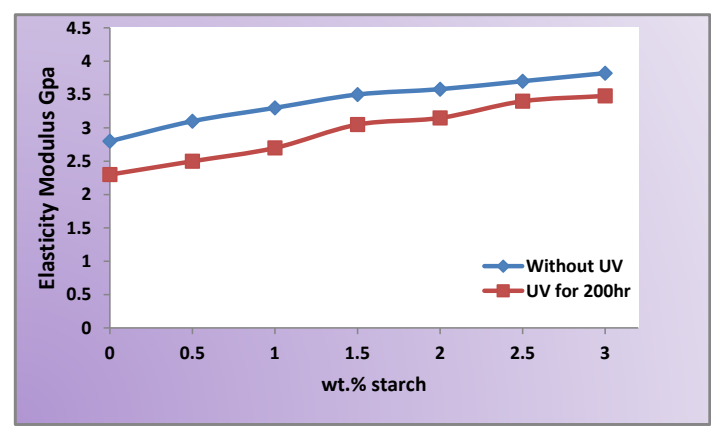

Figure 5: Modulus of elasticity of blend (Polyester: Starch) and weight fraction of starch powder.

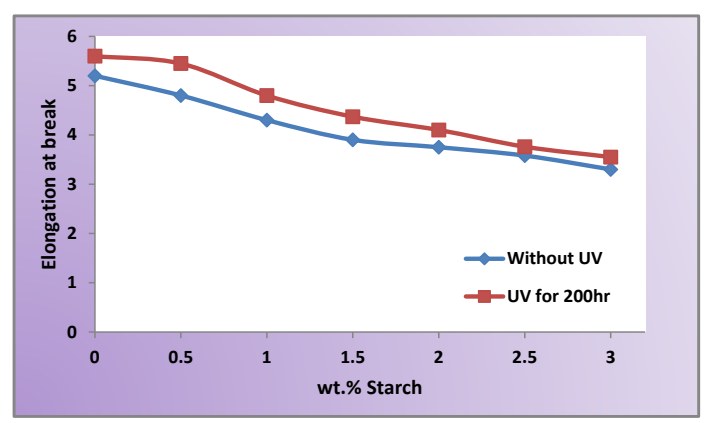

Figure 6: Elongation at break of blend (Polyester: Starch) and weight fraction of starch powder.

\section{5-2 Flexural Test Results}

The flexural (bending) strength and flexural (bending) modulus of blend (polyester: starch) were shown in Figs. (7 and 8). It has been observed from Fig. (7) that the flexural strength for both groups of polymer blend increases with adding of starch powders in unsaturated polyester until the weight fraction of the starch reach to $1 \%$ ratio and then decreased as weight fraction of starch powders increased in the polymer blend. Also, it has been observed from Fig. (8) that the flexural modulus, for both groups of polymer blend increases with increasing of starch powders in unsaturated polyester until reach the weight fraction of starch powders to (1.5\%) ratio and 
then decreased as starch powders weight fraction increased in the polymer blend.

Also, it has been showed that an increase in the values of flexural strength and flexural modulus for polymer blend samples which was loaded by starch powder and did not exposed to UV irradiation, as compared with their counterparts of polymer blend samples which has exposed directly to UV irradiation as shown in Figs. (7) and (8) respectively, and that related to absorb the ultraviolet (UV) radiation and then undergo photolytic reactions and that result in the a photodegradable in polymer blend samples [11], then the degraded sites act as stress concentrators and microcrack will occur when the material is subjected to stress. Thus, they diminish the flexural strength and flexural modulus causes the mechanical failure of the material.

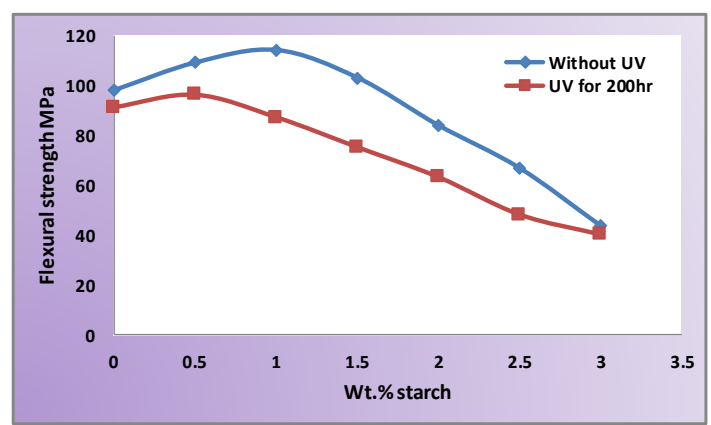

Figure 7: Flexural strength of blend (Polyester: Starch) and weight fraction of starch powder.

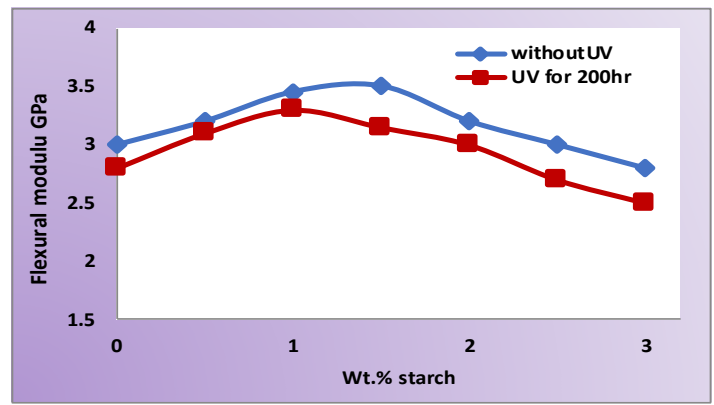

Figure 8: Flexural modulus of blend (Polyester: Starch) and weight fraction of starch powder.

\section{5-3 Impact Test Results}

The impact properties, which include impact strength and fracture toughness of unsaturated polyester blend are show in Figs. (9 and 10). It has been illustrated from Fig. (9) the impact strength for both groups of polymer blend increases with adding of starch powders in unsaturated polyester until to reach to the weight fraction (1\%) and then decreased as starch powders weight fraction increased in the polymer blend. Also, it has been observed from Fig. (10) that the fracture toughness, for both groups of polymer blend increases with increasing of starch powders in unsaturated polyester until to reach to the (1\%) weight fraction and then decreased as starch powders weight fraction increased in the polymer blend. Also, it has been seen that an increase in the values of impact strength for polymer blend which was loaded by starch powder and has not exposed to UV irradiation, slightly higher than impact strength values of polymer blend which has exposed directly to UV irradiation as shown in Fig. (9).

Furthermore, it has been noticed that there was an increase in fracture toughness values for polymer blend which was loaded by starch powder and has not exposed to UV irradiation, slightly higher than fracture toughness values of polymer blend which has exposed directly to UV irradiation as noted in Fig. (10). UV irradiation lead to a breakage the main and secondary bonds as a result of absorption of photons by polymer chains when exposure to ultraviolet (UV) radiation, as well as degraded sites act as stress concentrators and crack will occur when the material is subjected to stress. Thus, they diminish in impact strength and fracture toughness and that ultimately lead to mechanical failure of the material as previously mentioned [13 and 14].

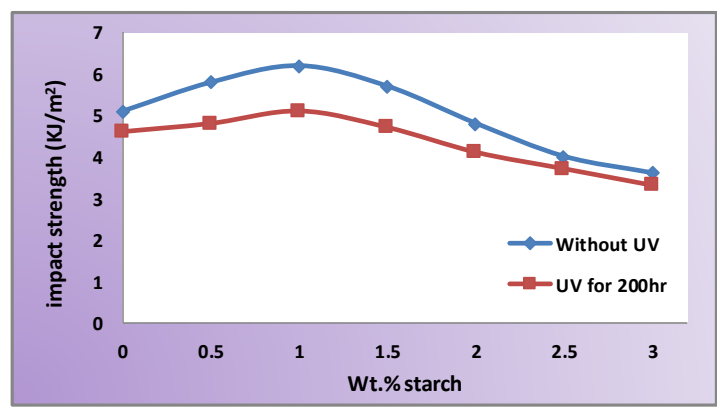

Figure 9: Impact strength of blend (Polyester: Starch) and weight fraction of starch powder.

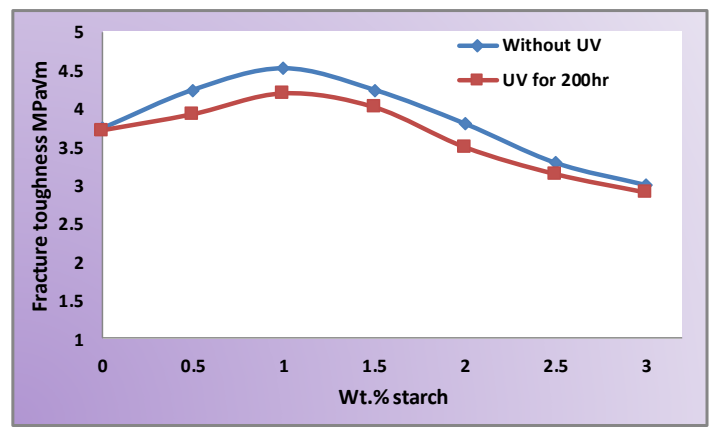

Figure 10: Fracture toughness of blend (Polyester: Starch) and weight fraction of starch powder.

\section{5-4 Hardness Test Results}

Hardness (Shore-D) of unsaturated polyester blend is shown in the Fig. (11). It has been observed from Fig. (11) that the hardness values for both groups of polymer blend increases with adding of starch powders in unsaturated polyester 
until to reach to the weight fraction (1\%) and then decreased as starch powders weight fraction increased in polymer blend. Also it has been noticed that there was an increase in hardness values for polymer blend which was loaded by starch powder and did not exposed to UV irradiation, slightly higher than hardness values of polymer blend which has exposed directly to UV irradiation as shown in Fig. (11).

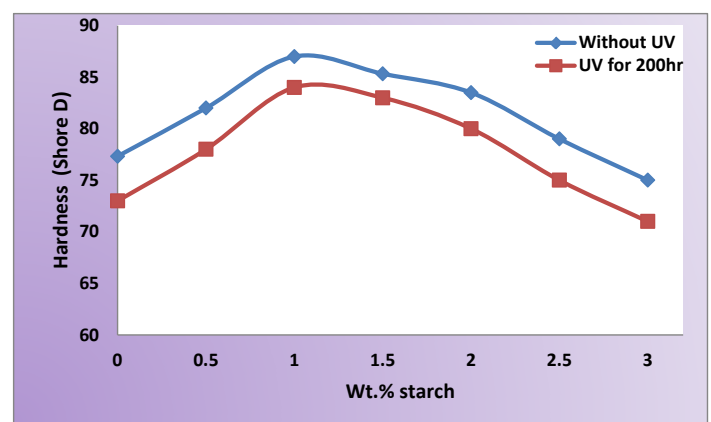

Figure 11: Hardness (Shore-D) of blend (Polyester: Starch) and weight fraction of starch powder.

\section{6- Conclusions}

According to the experimental results of polymer blend (unsaturated polyester: starch powders), can be the conclusions the following sentences:

1- The mechanical properties values of the polymer blend were found to be a function of the particles size, dispersion of starch powder with the unsaturated polyester matrix.

2- There is a significant decrease in some properties values such as (ultimate tensile strength and elongation percentage) of polymer blend (un-polyester: starch powders), with increasing of the weight fractions of starch powder.

3- There is a significant increase in modulus of elasticity of polymer blend (un-polyester: starch powders), with increasing of the of the weight fractions of starch powder. While the other properties values such as (hardness, impact strength, fracture toughness and flexural strength) for polymer blend (un-polyester : starch powders), increase with increasing of the weight fractions of starch powder reach to about (1 $\%)$, except the flexural modulus at (1.5\%), then decreasing in these values.

4- The effect of addition of (starch powder) on the most mechanical properties of blend specimens' is more than pure polyester matrix.

5- The using UV irradiations have a noticeable effect on the most mechanical properties of blend specimens'.

\section{References}

[1] Deshmukh S. P., Rao A. C., V. R. Gaval, Joseph Seena, Mahanwar P.A. 2, "Effect of Particle Size and Concentration on Mechanical and Electrical Properties of the Mica Filled PVC”, Journal of Minerals \& Materials Characterization \& Engineering, Vol. (9), No. (9), pp. (831), (2010).

[2] Sihama E. Salih, Hanaa A. Al-Kaisy, Sarmad. I. Ibrahim, "Effect of Reinforced System by Palm Fibers on the Mechanical and Insulation (Thermal and Acoustic) Properties for Polymer Composite Materials", Eng. \& Tech. Journal, Vol. (31), No. (2), pp. (217-234), (2013).

[3] Sihama I. Salih, "Acoustic and Mechanical Properties of Polymer Composites Reinforced by Pre-Deformed Palm Fiber", Eng. \& Tech. Journal, Vol. (31), No. (3), pp. (484-499), (2013).

[4] Alaa A. Abdul-Hamead, Thekra Kasim, and Awattiff A. Mohammed, "Mechanical Properties for Polyester Resin Reinforce with

Fe Weave Wire", International Journal of Application or Innovation in Engineering \& Management (IJAIEM), Vol. (3), No. (7), (2014).

[5] C. S. Obayi, A. O. Odukwe and D.O.N. Obikwelu, "Some Tensile Properties of Unsaturated Polyester Resin Reinforced with Varying Weight Fractions of Carbon Black Nanoparticles", Nigerian Journal of Technology, Vol. (27), No. (1), (2008).

[6] Annual Book of ASTM Standard, "Standard Test Method for Tensile Properties of Plastics D 638-03”, Vol. (08.01), pp. (1-12), (2003).

[7] S. I. Salih, J. K. Oleiwi and Q. A. Hamad, "Comparative Study the Flexural Properties and Impact Strength for Pmma Reinforced by Particles and Fibers for Prosthetic Complete Denture Base", the Iraqi Journal for Mechanical and Material Engineering, Vol. (15), No. (4), pp. (288-307), (2015).

[8] Annual Book of ASTM Standard, "Standard Test Method for Plastics PropertiesDurometer Hardness", D 2240-03, PP. (112), (2003).

[9] Premamoy Ghosh, "Polymer Science and Technology Plastics, Rubbers, Blends and Composites", Second Edition, Tata $\mathrm{Mx}$ Graw-hill, (2002).

[10] W. F. Smith and J. Hashemi, "Foundations of Materials Science and Engineering", Fourth Edition, McGraw-Hill, (2006).

[11] Jun Zhao, Gaochuang Cai, Lu Cui, Amir Si Larbi and Konstantinos Daniel Tsavdaridis, "Deterioration of Basic Properties of the Materials in FRP-Strengthening RC 
Structures under Ultraviolet Exposure", No. (9), pp. (402-420), Polymers (2017).

[12] Carlos Cadena, Delicia Acosta, "Effects of Solar UV Radiation on Materials Used in Agricultural Industry in Salta, Argentina: Study and Characterization", Journal of Materials Science and Chemical Engineering, No. (2), pp. (1-14), (2014).

[13] N. A. Saad, M. H. Al-Maamory, M. R. Mohammed, A. A. Hashim, "The Effect of Several Service and Weathering Parameters on Tensile Properties of PVC Pipe Materials", Materials Sciences and Applications Journal, No. (3), pp. (784-792), (2012).

[14] Lina Fadhil Kadhim, "Mechanical Properties of High Density Polyethylene/Chromium Trioxide under Ultraviolet Rays", International Journal of Applied Engineering Research, Vol. (12), No. (10), pp. (25172526), (2017).

\section{تأثير الأشعة الفوق البنفجية المعجلة على الخواص الميكانيكية للخلانط البوليمرية المكونه من (البولي أستر والنشأ)}

شفاء نايف عبدالجبار

\author{
قحطان عدنان حمد \\ سهامة عيسى صالح \\ قسم هندسة المواد الجامعة التكنولوجية
}

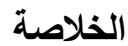

يغطي هذا البحث عملية خلط البولي استير غير المشبع مع مسحوق النشأ بشكل خلائط بوليمرية ودر اسة تاثير التشعيع بالأشعة فوق البنفسجية

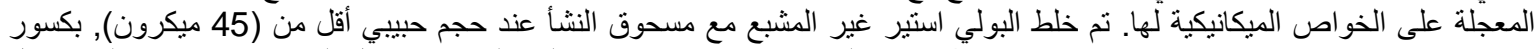

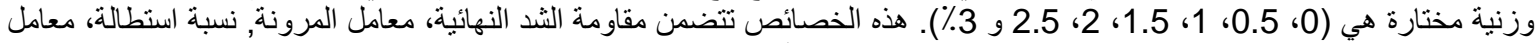

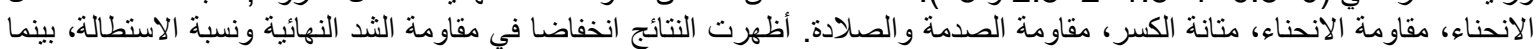

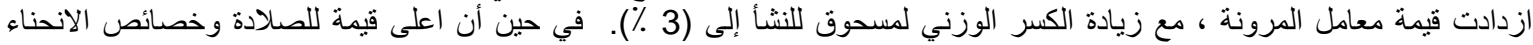
و الصدمة نحصل عليها عند كسر وزني (1 ٪) لهذه الخلائط البوليمرية. 